\title{
Serum concentration of hs-CRP in obese individuals with and without metabolic syndrome and its association with parameters of metabolic syndrome
}

\author{
Mahmood Mirhoseini ${ }^{*}{ }^{\mathbb{D}}$, Hamid Daemi $^{2}$, Mahshid Masoom Babaiee ${ }^{3}$, Majid Asadi-Samani ${ }^{4}$, Leilaassadat \\ Mirhoseini $^{5}$, Morteza Sedehi ${ }^{2}$
}

${ }^{1}$ Shiraz University of Medical Sciences, Shiraz, Iran

${ }^{2}$ Medical Plants Research Center, Basic Health Sciences Institute, Shahrekord University of Medical Sciences, Shahrekord, Iran

${ }^{3}$ Cellular and Molecular Research Center, Basic Health Sciences Institute, Shahrekord University of Medical Sciences, Shahrekord, Iran

${ }^{4}$ Students Research Committee, Shahrekord University of Medical Sciences, Shahrekord, Iran

${ }^{5}$ Arak University of Medical Sciences, Arak, Iran

\section{A R T I C L E I N F O}

\section{Article Type:}

Original

\section{Article History:}

Received: 7 October 2017

Accepted: 28 March 2018

Published online: 6 May 2018

\section{Keywords:}

Metabolic syndrome

Inflammatory markers

Metabolic parameters

Vitamin D

\begin{abstract}
A B S T R A C T
Introduction: Serum level of high sensitivity C-reactive protein (hs-CRP), as an inflammatory marker, can play a role in development of metabolic syndrome in obese individuals.

Objectives: This study aimed to determine serum concentration of hs-CRP in obese patients with metabolic syndrome and determine the association of this factor with factors involved in the progression of metabolic syndrome.

Patients and Methods: In this study, samples were selected by convenient method from obese patients, admitted to Kashani and Hajar hospitals (Shahrekord, Iran). First, based on NCEP-ATPIIIdefined metabolic syndrome, parameters of metabolic syndrome and serum levels of vitamin D were measured and a questionnaire containing demographics was completed for each participant. Accordingly, the samples ( $n=192)$ were divided into two identical groups; obese individuals without metabolic syndrome (controls) and obese individuals with metabolic syndrome (case group). HsCRP levels were measured in both groups.

Results: Serum level of hs-CRP in the case group was $17.58 \pm 1.40 \mu \mathrm{g} / \mathrm{mL}$ and in the control group was $9.04 \pm 1.26 \mu \mathrm{g} / \mathrm{mL}$, which was significantly higher in the case group than the control group $(P<0.001)$. Serum concentration of hs-CRP in case and control subjects had a negative significant correlation with vitamin D $(P<0.001)$, however, serum level of hs-CRP had no significant association with high density lipoprotein cholesterol (HDL-C), triglyceride (TG), fasting blood sugar (FBS), abdominal circumference, body mass index (BMI), and height $(P>0.05)$.

Conclusion: Hs-CRP can be used for prognosis and early detection of patients at risk of metabolic syndrome.
\end{abstract}

\footnotetext{
Implication for health policy/practice/research/medical education:

Inflammatory markers can be considered as risk factors for the development of metabolic syndrome in obese subjects. The present study confirms the role of hs-CRP as an inflammatory marker in the progression of metabolic syndrome in obese patients and its association with vitamin $\mathrm{D}$ deficiency that can play a significant role in prevention and control of metabolic syndrome in obese individuals.

Please cite this paper as: Mirhoseini M, Daemi H, Masoom Babaiee M, Asadi-Samani M, Mirhoseini L, Sedehi M. Serum concentration of hs-CRP in obese individuals with and without metabolic syndrome and its association with parameters of metabolic syndrome. J Renal Inj Prev. 2018;7(4):297-300. DOI: 10.15171/jrip.2018.65.
}

\section{Introduction}

Metabolic syndrome is a serious complication that develops following a sedentary lifestyle and poor nutrition. This syndrome was first introduced in 1998 as one of the background factors contributing to cardiovascular diseases and diabetes (1) and is also known by other names, including syndrome $\mathrm{X}$, insulin resistance syndrome, deadly quartet, obesity-dyslipidemia syndrome, and Reaven's syndrome (2). The prevalence of metabolic syndrome is different due to differences in age and race of the studied population and the diagnostic criteria used in different parts of the world. 
However, increased urbanization, lack of mobility, stress, and consumption of fatty foods, high carbohydrates, and high calories caused a consistent increased rate of metabolic syndrome over the past 20 years all over the world. According to the recent researches, it involves up to $25 \%$ of the general population $(3,4)$. This syndrome includes a number of clinical findings and laboratory abnormalities, such as obesity (central, abdominal or visceral), increased activity of the sympathetic nervous system, hypertension, glucose intolerance, insulin resistance, compensatory hyperinsulinemia, type 2 diabetes, dyslipidemia (hypertriglyceridemia, elevated low or high density lipoprotein cholesterol [HDL-C]), fatty liver, impaired fibrinolysis, hyperuricemia, systemic inflammation, especially endothelial dysfunction and vascular inflammation (5). As defined by NCEP ATP-III (1), metabolic syndrome is diagnosed with at least 3 risk factors, including obesity, hypertriglyceridemia, low HDL cholesterol, hypertension, and hyperglycemia. However, identification of other causes of this syndrome can play an important role in awareness and early detection of this syndrome and its treatment control.

\section{Objectives}

In this regard, the study aimed to measure the serum concentration levels of high sensitivity C-reactive protein (hsCRP), as an inflammatory marker in obese patients without metabolic syndrome and the association between these factors and other metabolic factors involved in the development of metabolic syndrome.

\section{Patients and Methods Study population}

This cross-sectional study was conducted during 20162017 on patients admitted to Hajar and Kashani hospitals, eligible for inclusion, comprising of body mass index (BMI) $\geq 25 \mathrm{~kg} / \mathrm{m}^{2}$, age $>18$, and metabolic syndrome parameters. The exclusion criteria for this study consisted of having kidney or liver disease, using weight loss drugs, or other weight reduction interventions, using vitamin D supplements, being pregnant or breast-feeding, taking estrogen and progesterone pills in women and withdraw to continue the study, laboratory tests, or examinations. Sampling was based on convenient method. A total of 192 patients were selected based on inclusion/exclusion criteria and were considered as sample size. Serum lipids levels (HDL-C, LDL-C, and triglyceride [TG]) and Fasting blood sugar (FBS) of all patients were determined in venous blood samples and sent to the laboratory. Metabolic syndrome was defined based on NCEP ATP-III criteria. After identifying patients with metabolic syndrome, patients were divided into two groups; 96 patients (those with the metabolic syndrome and obesity) and 96 obese individuals (those with obesity and without the metabolic syndrome). The two groups were selected based on similar gender, age, occupation, physical activity, smoking, type of urban and rural population and educational level. In this study, vitamin D and hs-CRP levels were measured and the association between hs-CRP and metabolic syndrome parameters was determined in obese subjects.

\section{Ethical issues}

1) The research followed the tenets of the Declaration of Helsinki; 2) informed consent was obtained; and 3) This study was approved by the Ethics Committee of Shahrekord University of Medical Sciences (ethical code\# IRSKUMS.REC.1395.247).

\section{Statistical analysis}

Data were entered into an Excel database and then analyzed using the SPSS software version 22, using descriptive and inferential statistics, such as mean and standard deviation (SD), as well as $t$ test, chi-square and Pearson's correlation coefficients and $P<0.05$ was considered significant.

\section{Results}

A total of 192 patients participated in this study with mean age of $51.37 \pm 19.82$ years, who were divided into two groups, after synchronization. The mean age of patients in the case group was $50.09 \pm 1.94$ years and in the control group was $52.57 \pm 2.05$ years. There was no significant difference between the two groups in terms of height, weight, BMI, systolic hypertension, and abdominal circumference $(P<0.05)$.

Mean of serum level of hs-CRP in the case group was $17.58 \pm 1.40 \mu \mathrm{g} / \mathrm{mL}$ and in the control group was $9.04 \pm 1.26$ $\mu \mathrm{g} / \mathrm{mL}$, which was significantly higher in the case group than the control group $(P<0.001)$ with a maximum level of hs-CRP at $36.4 \mu \mathrm{g} / \mathrm{mL}$ and minimum at $0.1 \mu \mathrm{g} / \mathrm{mL}$. The distribution of hs-CRP in the groups is presented in Table 1.

Serum level of hs-CRP was inversely associated with vitamin $\mathrm{D}$ in case $(\mathrm{r}=-0.32)$ and control $(\mathrm{r}=-0.34)$ subjects, based on Pearson's correlation coefficient $(P<0.001)$. Also hs-CRP was significantly associated with weight in the control group $(\mathrm{r}=-0.31 ; P<0.001)$, but there was no significant association in the case group $(P>0.05)$. Serum level of hs-CRP had no significant association with HDL-C, TG, FBS, abdominal circumference, BMI, and height in the groups, based on Pearson's correlation coefficient $(P>0.05$, Table 2).

\section{Discussion}

This study aimed to determine serum concentration of hsCRP in obese patients without metabolic syndrome and its association with metabolic syndrome parameters. Serum concentration of hs-CRP was significantly higher in patients than the control group and there was a significant negative correlation between serum levels of vitamin D and hs-CRP. However, association of serum concentration of hs-CRP and other markers of metabolic syndrome was not statistically significant.

In the present study, serum levels of hs-CRP increased with decreased serum levels of vitamin $\mathrm{D}$ and since 
Table 1. Distribution of the frequency of hs-CRP levels in the study groups

\begin{tabular}{|c|c|c|c|}
\hline \multirow{2}{*}{ hs-CRP } & \multicolumn{2}{|l|}{ Groups } & \multirow[b]{2}{*}{ Total } \\
\hline & Patients with metabolic syndrome & Control (obese individuals without metabolic syndrome) & \\
\hline Low risk $(<1.0 \mu \mathrm{g} / \mathrm{mL})$ & $10(10.41 \%)$ & $32(33.33 \%)$ & $42(21.78 \%)$ \\
\hline Normal $(1-3 \mu \mathrm{g} / \mathrm{mL})$ & $12(12.50 \%)$ & $21(21.87 \%)$ & $33(17.18 \%)$ \\
\hline High risk (>3.0 $\mu \mathrm{g} / \mathrm{mL})$ & $74(77.08 \%)$ & $43(44.79 \%)$ & $117(60.93)$ \\
\hline Total & $96(100)$ & $96(100)$ & $192(100)$ \\
\hline
\end{tabular}

Table 2. Association of hs-CRP with vitamin D and metabolic syndrome parameters

\begin{tabular}{|c|c|c|c|c|c|c|}
\hline \multirow{2}{*}{ Groups } & & \multicolumn{5}{|c|}{ Variables } \\
\hline & & BMI $\left(\mathrm{kg} / \mathrm{m}^{2}\right)$ & FBS (mg/dL) & $\mathrm{TG}$ (mg/dL) & HDL-C (mg/dL) & Vitamin D (ng/dL) \\
\hline \multirow{2}{*}{$\begin{array}{l}\text { Patients with metabolic syndrome } \\
(n=96)\end{array}$} & $\begin{array}{l}\text { Pearson's correlation } \\
\text { coefficient }\end{array}$ & 0.03 & 0.08 & 0.16 & 0.18 & -0.32 \\
\hline & $P$ value & 0.77 & 0.43 & 0.10 & 0.06 & $<0.001$ \\
\hline \multirow{2}{*}{$\begin{array}{l}\text { Control (obese individuals without } \\
\text { metabolic syndrome; } n=96 \text { ) }\end{array}$} & $\begin{array}{l}\text { Pearson's correlation } \\
\text { coefficient }\end{array}$ & 0.16 & 0.01 & 0.09 & 0.11 & -0.34 \\
\hline & $P$ value & 0.09 & 0.85 & 0.34 & 0.24 & $<0.001$ \\
\hline
\end{tabular}

decreased vitamin D increases the serum levels of TG, BP, and FBS and reduces HDL-C and all these variables are effective in the incidence of cardiovascular diseases, it can be justified that decreased vitamin $\mathrm{D}$ increases the serum levels of hs-CRP and risk of cardiovascular diseases in patients with metabolic syndrome. In a study conducted by Salek-Zamani et al in 2011, no significant difference in serum levels of vitamin D and PTH between the group with metabolic syndrome and the control group was detected, but a significant difference in hs-CRP levels and insulin resistance (6) was seen among them. Additionally, Tamakoshi et al showed that many of the metabolic syndrome parameters have a significant association with increased levels of hs-CRP (7). The association between concentrations of inflammatory markers and metabolic syndrome and body mass index in 80 patients with metabolic syndrome and 160 healthy individuals showed an increased concentration of hs-CRP in patients and is directly associated in women with increased body mass index and in men with waist circumference (8). Zarkesh et al in a cross-sectional study found that the concentration of three inflammatory markers is associated with metabolic syndrome on a population of 365 adults who participated in Tehran lipid and glucose study and reported increased hs-CRP levels associated with metabolic risk factors (9). In another study by Majd et al in 2016 on the association between serum hs-CRP and metabolic syndrome, the results showed that the levels of this protein increased significantly in patients with metabolic syndrome, compared to the control group (10).

Totally, different studies showed the association between inflammation and metabolic syndrome. However, the causal relationship between inflammation and metabolic syndrome and mechanism of this association is of great importance. Recent studies presented that in the process of developing metabolic syndrome, white fat increases, permeability of cells increases, and there is an imbalance between pro-inflammatory and anti-inflammatory cytokines. Macrophage infiltration in adipose tissue provides a source of inflammatory signals, while fat tissue interferes in its metabolism and controls metabolic changes associated with obesity (11). Inflammatory signals or cytokines increase the expression of superficial molecules involved in inflammation on the endothelial cells, smooth muscle cells, and macrophages and triggers inflammation by some reactions that present as inflammation markers of hs-CRP. Overall, metabolic syndrome is a pre- inflammatory condition and adipose tissue leads to increased inflammation in individuals (12).

\section{Conclusion}

We concluded that decreased serum levels of vitamin $\mathrm{D}$ and increased serum levels of hs-CRP in patients with metabolic syndrome are inflammatory-dependent processes that can lead to various risks, including cardiovascular diseases and diabetes. Therefore, hs-CRP can be used in early diagnosis and screening patients at risk of developing metabolic syndrome, especially in highrisk individuals.

\section{Limitations of the study}

One of the limitations of the present study was that patients who were affected by cardiovascular and renal diseases or those needed hospitalization during the research were excluded from the study. The collaboration tendency of subjects hospitalized at Kashani and Hajar hospitals was another limitation.

\section{Acknowledgments}

This study is the result of a dissertation of Hamid Daemi 
(MD dissertation\# 1413) approved by the Shahrekord University of Medical Sciences. The authors hereby acknowledge the Research and Technology ViceChancellor at Shahrekord University of Medical Sciences, the colleagues, and all participants in the study.

\section{Authors' contribution}

$\mathrm{HD}, \mathrm{MM}$, and $\mathrm{MMB}$ conducted the research and contributed to the conception and design of the research. MAS and LM prepared the primary draft. HD contributed to the acquisition of data. MS contributed to the analysis of data. All authors contributed to the drafting of the manuscript and final approval of the manuscript.

\section{Cocflicts of interest}

The authors declare that they have no competing interest.

\section{Ethical considerations}

Ethical issues (including plagiarism, misconduct, data fabrication, falsification, double publication or submission, redundancy) have been completely observed by the authors.

\section{Funding/Support}

The presented study has been supported and funded by the Research Deputy of Shahrekord University of Medical Sciences (Grant \# 2322).

\section{References}

1. Chuo S-K, Li J-C, Tsai W-C, Wu D-A, Kuo S-W, Pei D, et al. Correlations between white blood cell count and metabolic syndrome in middle-age Taiwanese. Endocrine Res. 2005; 31:39-50. doi: 10.1080/07435800500229151.

2. Kelishadi R, Ardalan G, Gheiratmand R, Adeli K, Delavari A, Majdzadeh R. Paediatric metabolic syndrome and associated anthropometric indices: the CASPIAN Study. Acta Paediatr. 2006;95:1625-34.doi:10.1080/08035250600750072.

3. Procopiou M, Philippe J. The metabolic syndrome and type
2 diabetes: epidemiological figures and country specificities. Cerebrovas Dis. 2005; 20:2-8. doi:10.1159/000088231.

4. Ebrahimi-Mamaghani M, Arefhosseini S, Golzarand M, Aliasgarzadeh A, Vahed-Jabbary M. Long-term effects of processed Berberis vulgaris on some metabolic syndrome components. Iranian J Endocrinol Metabol. 2009;11:12-8.

5. Klage JM. Epidemiology of cardiovascular diease. In: Goldman L, Schafer IA, eds. Cecil Medicine. USA: Saunders; 2011. pp. 256-9.

6. Salekzamani S, Neyestani TR, Alavi-Majd H, Houshiarrad A, Kalayi A, Shariatzadeh N, et al. Is vitamin D status a determining factor for metabolic syndrome? A case-control study. Diabetes Metab Syndr Obes. 2011;4:205-12. doi: 10.2147/DMSO.S21061.

7. Tamakoshi K, Yatsuya $\mathrm{H}$, Kondo T, Hori $\mathrm{Y}$, Ishikawa M, Zhang $\mathrm{H}$, et al. The metabolic syndrome is associated with elevated circulating C-reactive protein in healthy reference range, a systemic low-grade inflammatory state. Int J Obes Relat Metab Disord. 2003;27:443-9. di: 10.1038/ sj.ijo.0802260.

8. Hosseinpour-Niazi S, Alamdari S, Mirmiran P, HoseeiniEsfahani F, Azizi F. Inflammatory markers, the metabolic syndrome and body mass index in adults. Iranian J Endocrinol Met. 2013;15:237-43.

9. Faam B, Zarkesh M, Daneshpour MS, Azizi F, Hedayati M. The association between inflammatory markers and obesity-related factors in Tehranian adults: Tehran lipid and glucose study. Iranian J Basic Med Sci. 2014;17:577.

10. Mehrad Majd H, Bayat M, Ghayour Mobarhan M, Aziminezhad M, Borji A. Serum C-reactive protein level and its correlation with metabolic syndrome. J Neyshabur Univ Med Sci. 2016;4:1-8.

11. da Cruz LL, Cardoso LD, Pala D, de Paula H, Lamounier JA, Silva CA, et al. Metabolic syndrome components can predict $\mathrm{C}$ reactive protein concentration in adolescents. Nutr Hosp. 2013; 28: 1580-6. doi: 10.3305/nh.2013.28.5.6625.

12. Bremer AA, Jialal I. Adipose tissue dysfunction in nascent metabolic syndrome. J Obes. 2013;2:1-3. doi: $10.1155 / 2013 / 393192$.

Copyright $\odot 2018$ The Author(s); Published by Nickan Research Institute. This is an open-access article distributed under the terms of the Creative Commons Attribution License (http://creativecommons.org/licenses/by/4.0), which permits unrestricted use, distribution, and reproduction in any medium, provided the original work is properly cited. 